\title{
Field-Potential Evidence for Extrasynaptic Alterations in the Hippocampal CA1 Pyramidal Cell Population during
}

\section{Paired-Pulse Potentiation}

\author{
WALTER C. LOW, SPENCER L. BEMENT, AND DAVID WHITEHORN ${ }^{1}$ \\ Bioelectrical Sciences Laboratory, University of Michigan, Ann Arbor, Michigan 48105, and \\ Department of Physiology and Biophysics, University of Vermont, Burlington, Vermont 05405
}

Received April 16, 1982; revision received September 2, 1982

\begin{abstract}
The mechanisms of paired-pulse potentiation of the CAI pyramidal cell population were examined by determining input-output relations for control and potentiated responses originating from the activation of radiatum fibers in the hippocampal slice preparation. Two types of potentiation for synchronously discharging pyramidal cells (population spike) were observed. In the first type, the potentiation of the population spike was found to be a combination of synaptic and extrasynaptic factors. This form of potentiation was observed in 16 of 28 slices. In the second type, the potentiation of the population spike was attributed entirely to the potentiation of summated dendritic depolarizations (population EPSP). This synaptic process of potentiation was observed in 12 of 28 slices. The involvement of only extrasynaptic mechanisms in the paired-pulse potentiation of the population spike was not observed. For the potentiation originating from a combination of synaptic and extrasynaptic mechanisms, $60 \%$ of the potentiation of the population spike was a result of synaptic factors and $40 \%$ could be attributed to extrasynaptic factors. These results support the concept that alterations in the excitability of postsynaptic neurons serve as a component of the mechanisms of paired-pulse potentiation in the radiatum fiber-CA1 pyramidal cell system.
\end{abstract}

\section{INTRODUCTION}

The hippocampal formation provides a unique model for the study of cellular mechanisms of plasticity. Several forms of alterations in neural function can be elicited using the in vitro slice preparation $(13,17)$, and the

Abbreviations: EPSP—excitatory postsynaptic potential, $\mathrm{I} / \mathrm{O}$-input-output, r.u.-relative unit.

' This work was supported by U.S. Public Health Service grants GM 01289 and NS 08470. Please send correspondence to Walter C. Low, Ph.D., Department of Physiology and Biophysics, University of Vermont, Given Medical Bldg., Burlington, VT 05405. 
appropriate electrophysiologic responses can be monitored easily. A relatively simple form of plasticity is paired-pulse potentiation of the CA1 pyramidal cell population, which occurs when the fibers in stratum radiatum are electrically stimulated with paired-pulses separated by $40 \mathrm{~ms}$. With this interstimulus interval, the response to the second stimulus is significantly potentiated over control responses. This is true for the evoked responses recorded in the dendritic region of synaptic termination (population excitatory postsynaptic potential, EPSP) and in the region of the discharging pyramidal cell bodies (population spike).

There are three major transformations involved in these responses, each of which may be altered under paired-pulse conditions. First, the relationship between the intensity of the applied electrical stimulus and the degree of activation of the radiatum fibers can be altered as demonstrated by Low and BeMent (14). Second, the relationship between the magnitude of the afferent activity and the resulting summated synaptic activation can be altered as shown by Lomo (12) in the perforant path innervation of the dentate gyrus. Third, the relationship between the degree of summated synaptic activation and the summated impulse discharge of the associated neuronal population might be altered as seen in the tetanic activation of the perforant path-dentate pathway $(5,10,11)$.

We report here a systematic examination of the third possibility with paired-pulse activation of the radiatum fiber-CA1 pathway. In 28 slice preparations we determined the relationship between the magnitude of the population EPSP and that of the population spike both during control conditions (in response to the first of a pair of stimuli delivered to stratum radiatum) and during potentiation (in response to the second of the paired stimuli). We reasoned that if this relationship was altered such that larger population spikes were obtained for given amplitudes of population EPSPs during potentiation, it would indicate the presence of an increased excitability in the postsynaptic neurons at some point between the generation of the EPSP and initiation of the axonal spike. We found evidence for such an alteration in 16 of 28 slices. In these preparations we calculated that the extrasynaptic alteration accounted for approximately $40 \%$ of the observed potentiation of the population spike. Together with other recent data $(10,16)$, our findings suggest that CAl pyramidal cells are capable of modifying their response extrasynaptically to a given level of depolarization at synaptic sites.

\section{METHODS}

General

Hippocampal slices were prepared from Sprague-Dawley rats (100 to 125 g) as described elsewhere $(14,15)$. The rats were incapacitated with ether 
anesthesia or by a blow to the back of the shoulders. They were then quickly decapitated, the brains were removed from the base of the skull, and the hippocampal formation dissected free. Hippocampal sections (300 to 400 $\mu \mathrm{m}$ thick) were cut in planes transverse to the longitudinal axis and placed in a small petri dish filled with an aerated and cooled $\left(\sim 10^{\circ} \mathrm{C}\right)$ glucose medium (124 mM NaCl, $5 \mathrm{mM} \mathrm{KCl}, 1.24 \mathrm{mM} \mathrm{KH}_{2} \mathrm{PO}_{4}, 1.3 \mathrm{mM} \mathrm{MgSO}_{4}$, $2.4 \mathrm{mM} \mathrm{CaCl}_{2}, 26 \mathrm{mM} \mathrm{NaHCO}_{3}$ and $10 \mathrm{~mm}$ glucose). The sections were then transferred to an incubation and recording chamber, which consisted of two separate fluid compartments. The inner compartment, filled with the glucose medium, contained a nylon net upon which the slices were placed. The outer chamber contained distilled water maintained at $37 \pm 0.5^{\circ} \mathrm{C}$ by a heating filament. A gas mixture of $95 \% \mathrm{O}_{2}$ and $5 \% \mathrm{CO}_{2}$ was bubbled into the outer chamber to create an oxygen gradient that resulted in the diffusion of $\mathrm{O}_{2}$ into the slices. The slices were incubated approximately $45 \mathrm{~min}$ in the inner chamber, then visually guided recording electrodes were placed on the region of pyramidal cell bodies (stratum pyramidale) and the region of the radiatum fiber-CA1 pyramidal cell dendritic synapses (stratum radiatum). An insulated bipolar stimulating electrode (40-gauge Nichrome) was also placed in stratum radiatum, but more proximal to region $\mathrm{CA} 3$ than the recording electrode (Fig. 1).

An isolated constant current source driven by a Grass stimulator (model SD5) was used to excite the afferent radiatum fibers that terminated in the midapical dendritic region of the CAl pyramidal cell population. Current pulses of $100 \mu \mathrm{s}$ in duration and 10 to $200 \mu \mathrm{A}$ intensity were used to evoke responses from stratum radiatum and stratum pyramidale. The evoked responses from the two loci were recorded with glass microelectrodes ( 1 to 2 $\mathrm{m} \Omega$ ) filled with $2 \mathrm{M} \mathrm{NaCl}$. The pyramidale and radiatum responses were amplified by WPI (model DAM 4) and Transidyne (model 1600) electrometers, respectively, and simultaneously recorded on the FM channels of an HP 3960 tape recorder. With this stimulating and recording arrangement, paired stimuli separated by $40 \mathrm{~ms}$ were applied once every $2 \mathrm{~s}$. Input-output (I/O) relations between evoked radiatum and pyramidale responses were determined by increasing the stimulus intensity.

The recorded evoked responses were digitized and stored on disk files with an HP 21 MX computer system. The digitized responses were later analyzed to determine the evoked amplitudes of interest, using algorithms tailored to measure the negativity of the radiatum response $(1 \mathrm{~ms}$ after the stimulus artifact), and the peak negativity of the pyramidale response.

\section{Input-Output Functions of Potentiation}

The analysis of input-output functions was used to examine alterations in the relationship between the population EPSP and population spike. Such 


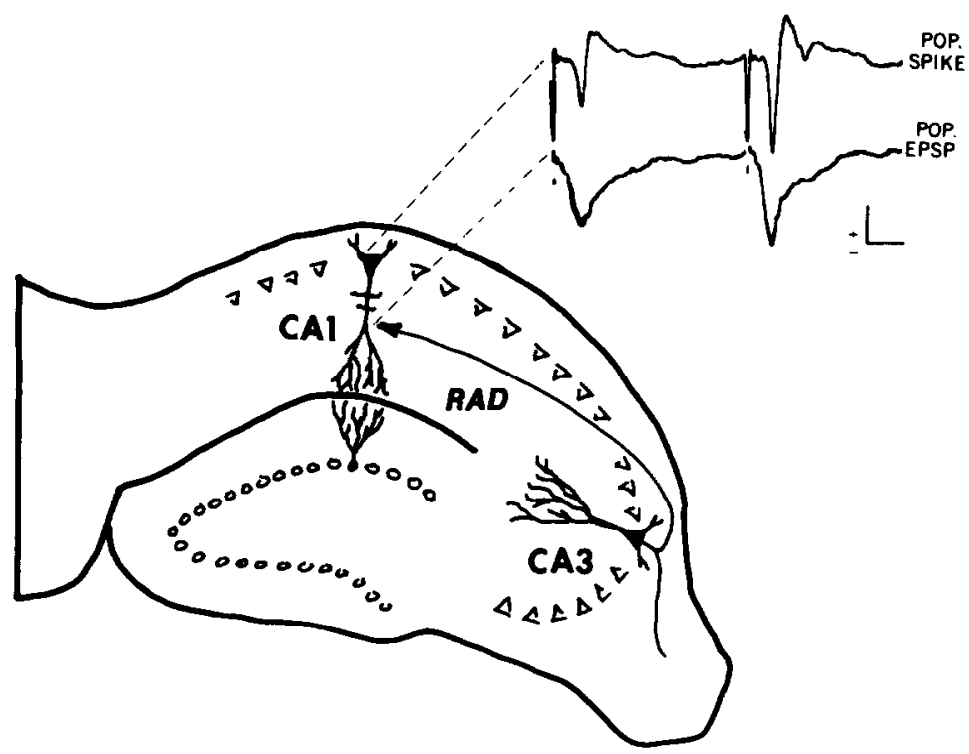

FIG. 1. Electrical stimulation and field potential recording from hippocampal slices. Stimulating electrode was placed on the radiatum fibers and two recording electrodes were placed in strata radiatum and pyramidale, respectively. The recording electrode in stratum radiatum detected the population EPSP and that in stratum pyramidale detected the population spike. Vertical bar, $1 \mathrm{mV}$; horizontal bar $5 \mathrm{~ms}$.

an approach can determine quantitatively the relative contribution of synaptic and extrasynaptic factors to the overall potentiation of the CAl population spike response.

The measures of input and output were obtained from the evoked responses in the regions of stratum radiatum and pyramidale, respectively. The amplitude of the summated EPSP and the peak negativity of the spike were used as measures of the respective input and output of the CA1 pyramidal cell population. Two linear regression equations were determined for the input-output relationship between these two evoked responses for a range of increasing stimulus intensities. The first input-output function described the relationship of the control population EPSP and spike, and the second input-output function described the relationship between the test population EPSP and spike evoked in response to an electrical stimulus applied $40 \mathrm{~ms}$ after the control stimulus.

If paired-pulse potentiation of the summated spike is simply a result of the potentiation of synaptic transmission, then the two input-output functions should be coincident, i.e., for a given potentiation in the summated EPSP the associated amplitude of the potentiated population spike would be 
equal to that predicted from the regression equation of the control responses. On the other hand, if the paired-pulse potentiation of the summated population spike is not simply a result of the potentiation of the summated EPSP, but also involves postsynaptic factors, then the two input-output functions should not be coincident, i.e., for a given potentiation of the summated EPSP, the associated amplitude of the potentiated population spike would be greater than the value predicted from the regression equation of the control responses.

A statistical measure was used to compare the regression equations for the test and control responses. Statistical comparisons were made of the slope and intercept, and therefore the coincidence, of regression equations of the form

and

$$
Y_{\mathrm{C}}=A_{\mathrm{C}}+B_{\mathrm{C}}\left(X_{\mathrm{C}}-\overline{X_{\mathrm{C}}}\right)
$$

$$
Y_{\mathrm{T}}=A_{\mathrm{T}}=B_{\mathrm{T}}\left(X_{\mathrm{T}}-\overline{X_{\mathrm{T}}}\right)
$$

where $A_{\mathrm{C}}$ and $A_{\mathrm{T}}$ are estimates of the intercepts for the control and test functions, $B_{\mathrm{C}}$ and $B_{\mathrm{T}}$ are estimates of the respective slopes, and $\overline{X_{\mathrm{C}}}$ and $\overline{X_{\mathrm{T}}}$ are mean values of the control and test population EPSP amplitudes. The statistical method of analysis is similar to that presented by Brownlee (6) and can briefly be described as follows.

The first step in the statistical comparison of two regression lines requires the analysis of the variance about the two lines. This is accomplished by determining:

(1) the sum of squares, $S S R$, about each regression line given as

$$
S S R_{\mathrm{C}}=\left(S P D_{\mathrm{C}}\right)^{2} /\left(S D X_{\mathrm{C}}\right), \quad S S R_{\mathrm{T}}=\left(S P D_{\mathrm{T}}\right)^{2} /\left(S D X_{\mathrm{T}}\right),
$$

(2) the residual sum of squares, RSS, about each regression line which is expressed as

$$
R S S_{\mathrm{C}}=S D Y_{\mathrm{C}}-S S R_{\mathrm{C}}, \quad R S S_{\mathrm{T}}=S D Y_{\mathrm{T}}-S S R_{\mathrm{T}},
$$

where $S D X$ is the sum of the squares of the $X$ deviations from the mean of the $X \mathrm{~s},\left[\Sigma\left(X_{\mathrm{i}}-\bar{X}\right)^{2}\right] ; S D Y$ is the sum of the squares of the $Y$ deviations from the mean of the $Y \mathrm{~s},\left[\Sigma\left(Y_{\mathrm{i}}-\bar{Y}\right)^{2}\right] ; S P D$ is the sum of the product of the deviations, $\left(\Sigma\left(X_{\mathrm{i}}-\bar{X}\right)\left(Y_{\mathrm{i}}-\bar{Y}\right)\right)$ and the subscripts $\mathrm{C}$ and $\mathrm{T}$ denote control and test variables respectively. The variance, $S^{2}$, about each of the regression lines can be expressed as

$$
S_{\mathrm{C}}^{2}=\left(R S S_{\mathrm{C}}\right) /\left(N_{\mathrm{C}}-2\right), \quad S_{\mathrm{T}}^{2}=\left(R S S_{\mathrm{T}}\right) /\left(N_{\mathrm{T}}-2\right)
$$

where $N_{\mathrm{C}}$ and $N_{\mathrm{T}}$ are, respectively, the number of control and test data points. 
In evaluating the similarity of slopes, the variance about each regression line is used to determine a joint variance, $S_{\mathrm{J}}^{2}$, expressed as

$$
S_{\mathrm{J}}^{2}=\frac{\left(N_{\mathrm{C}}-2\right) S_{\mathrm{C}}^{2}+\left(N_{\mathrm{T}}-2\right) S_{\mathrm{T}}^{2}}{N_{\mathrm{C}}-2+N_{\mathrm{T}}-2} .
$$

The slopes of the two regression lines, $B_{\mathrm{C}}$ and $B_{\mathrm{T}}$, are determined as follows:

$$
B_{\mathrm{C}}=\left(S P D_{\mathrm{C}}\right) /\left(S D X_{\mathrm{C}}\right), \quad B_{\mathrm{T}}=\left(S P D_{\mathrm{T}}\right) /\left(S D X_{\mathrm{T}}\right) .
$$

The variance associated with the null hypothesis of a similarity in slopes, $\left(H_{\mathrm{o}}: \beta_{\mathrm{C}}-\beta_{\mathrm{T}}=0\right)$, is given as

$$
V B B=S_{\mathrm{J}}^{2}\left[\frac{1}{S D X_{\mathrm{C}}}+\frac{1}{S D X_{\mathrm{T}}}\right] .
$$

Thus, the $t$ statistic used to test the null hypothesis regarding the similarity of slopes, $\left(H_{\mathrm{o}}: \beta_{\mathrm{C}}-\beta_{\mathrm{T}}=0\right)$, is

$$
t\left(N_{\mathrm{C}}+N_{\mathrm{T}}-4\right)=\left(B_{\mathrm{C}}-B_{\mathrm{T}}\right) /(V B B)^{1 / 2} .
$$

If the null hypothesis is rejected, then the two regression lines differ in slope. However, if the hypothesis is accepted, then the similarity of intercepts can be tested.

The similarity of intercepts is evaluated by first determining a joint slope, $B_{\mathrm{J}}$, given by the expression

$$
B_{\mathrm{J}}=\left(S P D_{\mathrm{C}}+S P D_{\mathrm{T}}\right) /\left(S D X_{\mathrm{C}}+S D X_{\mathrm{T}}\right) .
$$

A new residual sum of squares, $R$, about the two parallel regression lines is also computed from the expression

$$
R=S D Y_{\mathrm{C}}+S D Y_{\mathrm{T}}-\frac{\left(S P D_{\mathrm{C}}+S P D_{\mathrm{T}}\right)^{2}}{\left(S D X_{\mathrm{C}}+S D X_{\mathrm{T}}\right)} .
$$

The new residual sum of squares is used to compute a new joint variance,

$$
N S_{\mathrm{J}}^{2}=\frac{R}{\left(N_{\mathrm{C}}+N_{\mathrm{T}}-3\right)} .
$$

Therefore, the $t$ statistic used to test the hypothesis involving the similarity of intercepts, $\left(H_{\mathrm{v}}: \alpha_{\mathrm{C}}-\alpha_{\mathrm{T}}=0\right)$, is

$$
t\left(N_{\mathrm{C}}+N_{\mathrm{T}}-3\right)=\frac{\left(\bar{Y}_{\mathrm{C}}-\bar{Y}_{\mathrm{T}}\right)-B_{\mathrm{J}}\left(\bar{X}_{\mathrm{C}}-\bar{X}_{\mathrm{T}}\right)}{N S_{\mathrm{J}}\left[\frac{1}{N_{\mathrm{C}}}+\frac{1}{N_{\mathrm{T}}}+\frac{\left(\overline{X_{\mathrm{C}}}-\overline{X_{\mathrm{T}}}\right)}{S D X_{\mathrm{C}}+S D X_{\mathrm{T}}}\right]^{1 / 2}}
$$




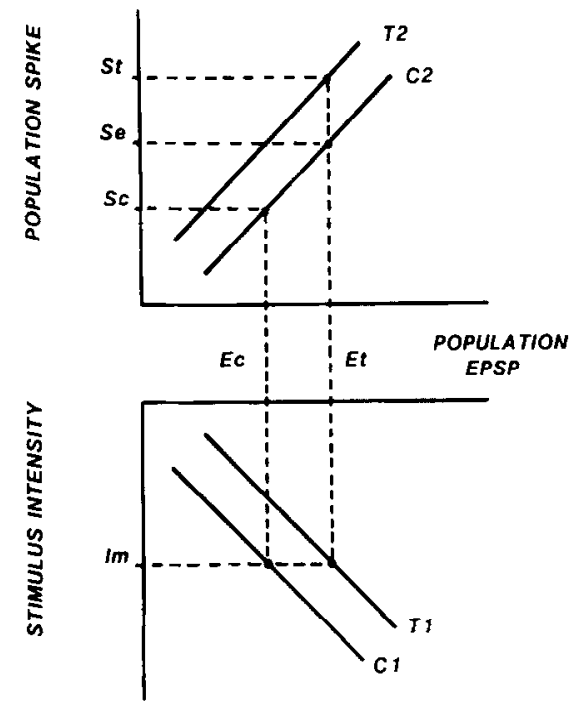

FIG. 2. Determination of percentage of potentiation attributed to synaptic and extrasynaptic factors. Control $\left(E_{\mathrm{c}}\right)$ and test $\left(E_{\mathrm{v}}\right)$ population EPSPs can be determined for a given midrange stimulus intensity $\left(I_{\mathrm{m}}\right)$ from hypothetical control $(C l)$ and test $(T I)$ stimulus intensity-population EPSP relations. These amplitudes for the population EPSPs are then used to determine the control and expected population spike amplitudes $\left(S_{\mathrm{c}}\right.$ and $S_{\mathrm{e}}$ respectively) from the control population EPSP-spike relation (C2). Similarly, the amplitude for the test population EPSP is also used to determine the test value for the population spike amplitude $\left(S_{t}\right)$ from the test population EPSP-spike relation (T2). The control, expected, and test values of the population spike amplitudes are used in the determination of the percentage of the total potentiation attributed to synaptic and postsynaptic factors as discussed in the text.

where $\bar{X}$ and $\bar{Y}$ are the means of the $X$ and $Y$ values, respectively. If the null hypothesis is rejected, then the parallel regression lines differ in intercept. If the null hypothesis is accepted then the lines are coincident.

The input-output functions and the statistical test of significance were used to determine the percentage of the population spike potentiation which could be attributed to synaptic factors, $\% P(\operatorname{syn})$, and postsynaptic factors, $\% P$ (postsyn) (see Fig. 2). These percentages were determined by first establishing the midrange amplitude $\left(I_{\mathrm{m}}\right)$ of the stimulus intensities. This value was then used to determine the corresponding control and test population EPSP values ( $E_{\mathrm{c}}$ and $E_{\mathrm{t}}$, respectively) from the corresponding control and test stimulus population EPSP regression equations. The control and test values for the population EPSP was then used to determine the control and expected test population spike amplitudes ( $S_{\mathrm{c}}$ and $S_{\mathrm{e}}$, respectively) from the control population EPSP-spike relation. Similarly, the value for the test population EPSP amplitude was used to determine the value of the test 


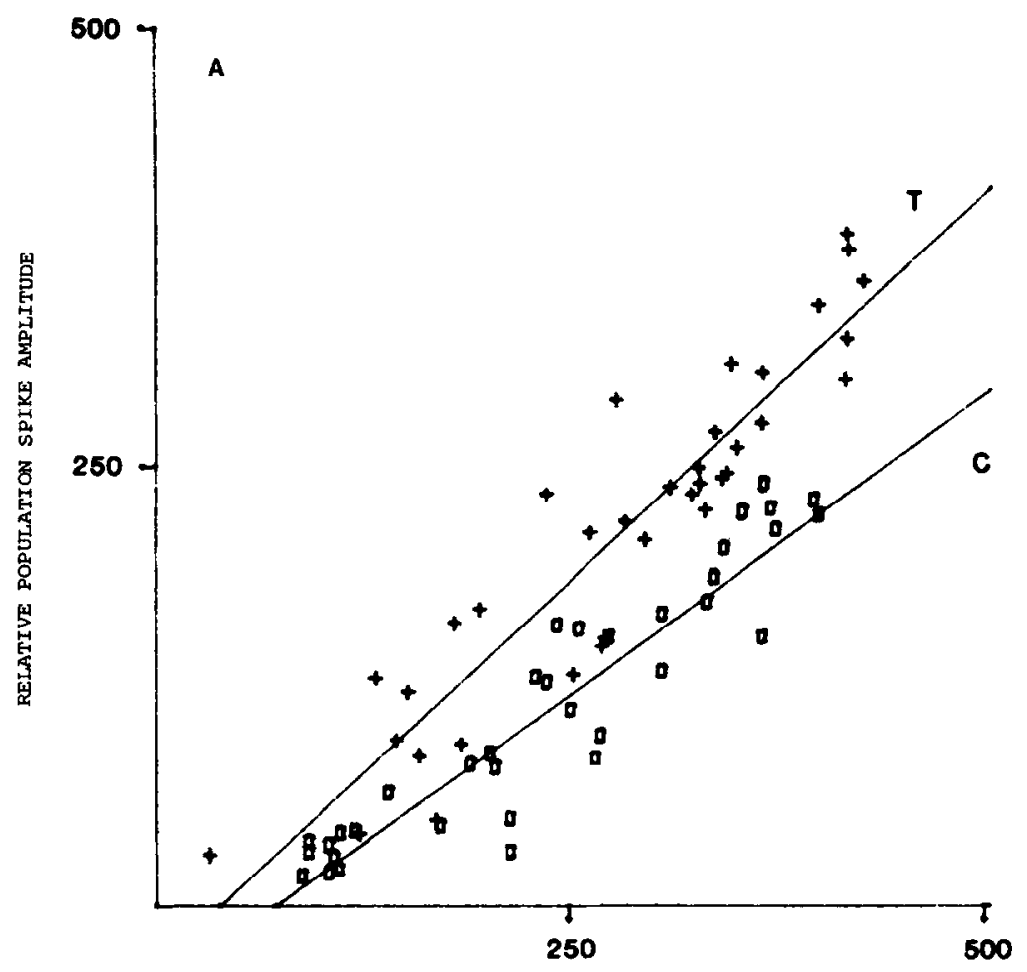

RELATIVE POPULATION EPSP AMPLITUDE

FIG. 3. A-noncoincident control and test input-output (I/O) functions. $\mathrm{I} / \mathrm{O}$ relations between population EPSP and spike with control regression line $C$ is associated with control responses (squares); and test regression line $\mathrm{T}$ with test responses (crosses). Number of control values, 35; test values, 35. Correlation coefficient for control responses, 0.937; test responses, 0.930. Population EPSP: 500 relative units, $2.8 \mathrm{mV}$; population spike: 500 relative units, $2.0 \mathrm{mV}$. Bcoincident control and test I/O functions. I/O relations between the population EPSP and spike with control regression line $C$ is associated with control responses (squares); and test regression line $T$ with test responses (crosses). Number of control values, 49; test values, 49. Correlation coefficient for control responses, 0.960 ; for test responses, 0.978. Population EPSP: 500 relative units, $2.7 \mathrm{mV}$; population spike: 500 relative units, $6.2 \mathrm{mV}$.

population spike $\left(S_{\mathrm{t}}\right)$. Using these values, the percentage of the total population spike potentiation that is attributed to synaptic factors can then be expressed as

$$
\% P(\text { syn })=\left[\left(S_{\mathrm{e}}-S_{\mathrm{c}}\right) /\left(S_{\mathrm{t}}-S_{\mathrm{c}}\right)\right] \times 100 \%
$$

and the percentage of the total population spike that is attributed to postsynaptic factors can be expressed as

$$
\% P(\text { postsyn })=\left[\left(S_{\mathrm{t}}-S_{\mathrm{e}}\right) /\left(S_{\mathrm{t}}-S_{\mathrm{c}}\right)\right] \times 100 \%
$$




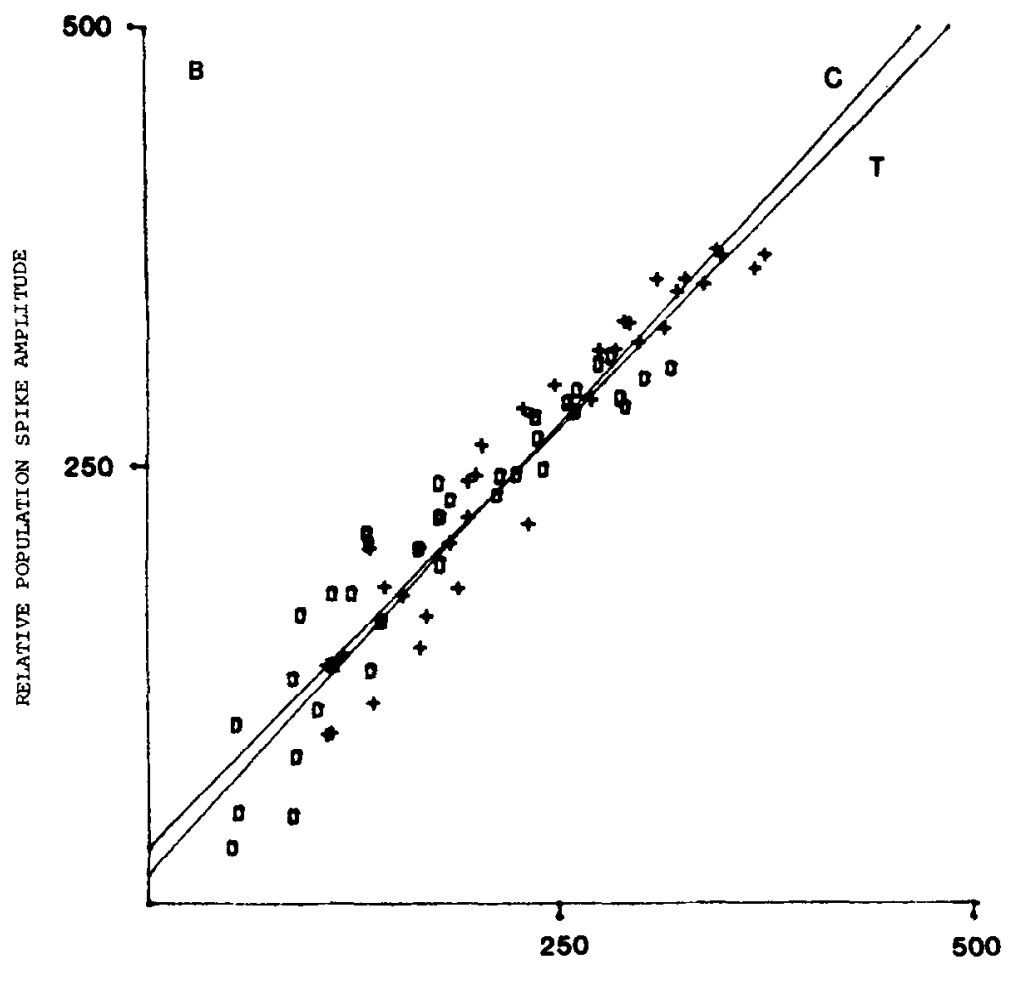

RELATIVE POPULATION EPSP AMFLITUDE

Figure 3 (Continued)

\section{RESULTS}

In all slices examined, potentiation was observed for both the population spike and EPSP with paired stimuli. However, two relationships between the control and test EPSP-spike functions were found. The first relationship was characterized by test I/O equations, which exhibited slopes and/or intercepts that were significantly greater than those of the control I/O equations (Fig. $3 \mathrm{~A})$. This type of relationship was seen in 16 of 28 slices and is consistent with the notion of extrasynaptic alterations in potentiation. Of these 16 slices, 8 exhibited significant differences in slope and intercept and 8 exhibited significant differences in intercept alone.

The second type of relationship was one in which the control and test I/O equations were statistically coincident (Fig. 3B) in that hypotheses of similarities in slopes and intercepts for the respective regression equations could not be rejected at the 0.05 level of significance. This lack of dissociation between the test and control equations was observed in 12 of 28 slices and 
is consistent with mechanisms of potentiation which are entirely synaptic in nature.

The percentage of the population spike potentiation that can be attributed to synaptic factors and postsynaptic factors was determined for the 16 "noncoincident" I/O pairs. An example of one such percentage determination is illustrated in Fig. 4. The midrange value of the stimulus intensity $\left(I_{\mathrm{m}}\right)$ was determined to be $77.5 \mu \mathrm{A}$ for the linear range of the stimulus-population EPSP relation. This value was used in the control and test regression equations for regression lines $C 1$ and $T 1$ to determine the amplitudes in terms of relative units (r.u.) for the control and test population EPSP amplitudes ( $E_{\mathrm{c}}=186$ r.u. and $E_{\mathrm{t}}=264$ r.u. respectively). These control and test population EPSP values in turn were used to compute the relative control and expected test spike amplitudes $\left(S_{\mathrm{c}}=107\right.$ r.u. and $S_{\mathrm{e}}=158$ r.u., respectively) from the regression equation for the control regression line $C 2$. The amplitude of the test population EPSP was also used to compute the test spike amplitude $\left(S_{\mathrm{t}}=191 \mathrm{r}\right.$.u. $)$ from the regression equation for the test regression line $T 2$. Thus for this $\mathrm{I} / \mathrm{O}$ pair the percentage of the total population spike potentiation was determined to be $61 \%$ for synaptic factors and $39 \%$ could be attributed to postsynaptic factors.

The percentage of the total potentiation that can be attributed to postsynaptic and synaptic factors for the 16 slices that exhibited noncoincident $\mathrm{I} / \mathrm{O}$ functions is shown in Fig. 5 . The mean and standard error of the postsynaptic contribution was determined to be $40 \pm 5 \%$, and the mean and standard error of the synaptic contribution was determined to be $60 \pm 5 \%$.

\section{DISCUSSION}

Our results support the concept that postsynaptic mechanisms contribute to the potentiation of the discharge of hippocampal pyramidal cells with paired-pulse stimulation. We take the dissociation of test and control I/O functions for 16 of 28 slices as indicative of the existence of an extrasynaptic component. The mean percentage of the total potentiation of the population spike originating from postsynaptic factors was $40 \pm 5 \%$ and that attributed to synaptic factors was $60 \pm 5 \%$, as determined from 16 pairs of noncoincident $\mathrm{I} / \mathrm{O}$ functions. The existence of such an extrasynaptic component suggests a functional alteration in the relationship between synaptic activation and the discharge of pyramidal cells.

The possibility of extrasynaptic factors in potentiation was suggested by Andersen et al. (1) and Lomo (12). Both found an enhancement of the pyramidal and granule cell population spike without an associated enhancement of the population EPSP when the population was first conditioned with antidromic stimulation. Such an enhancement could be explained by an 


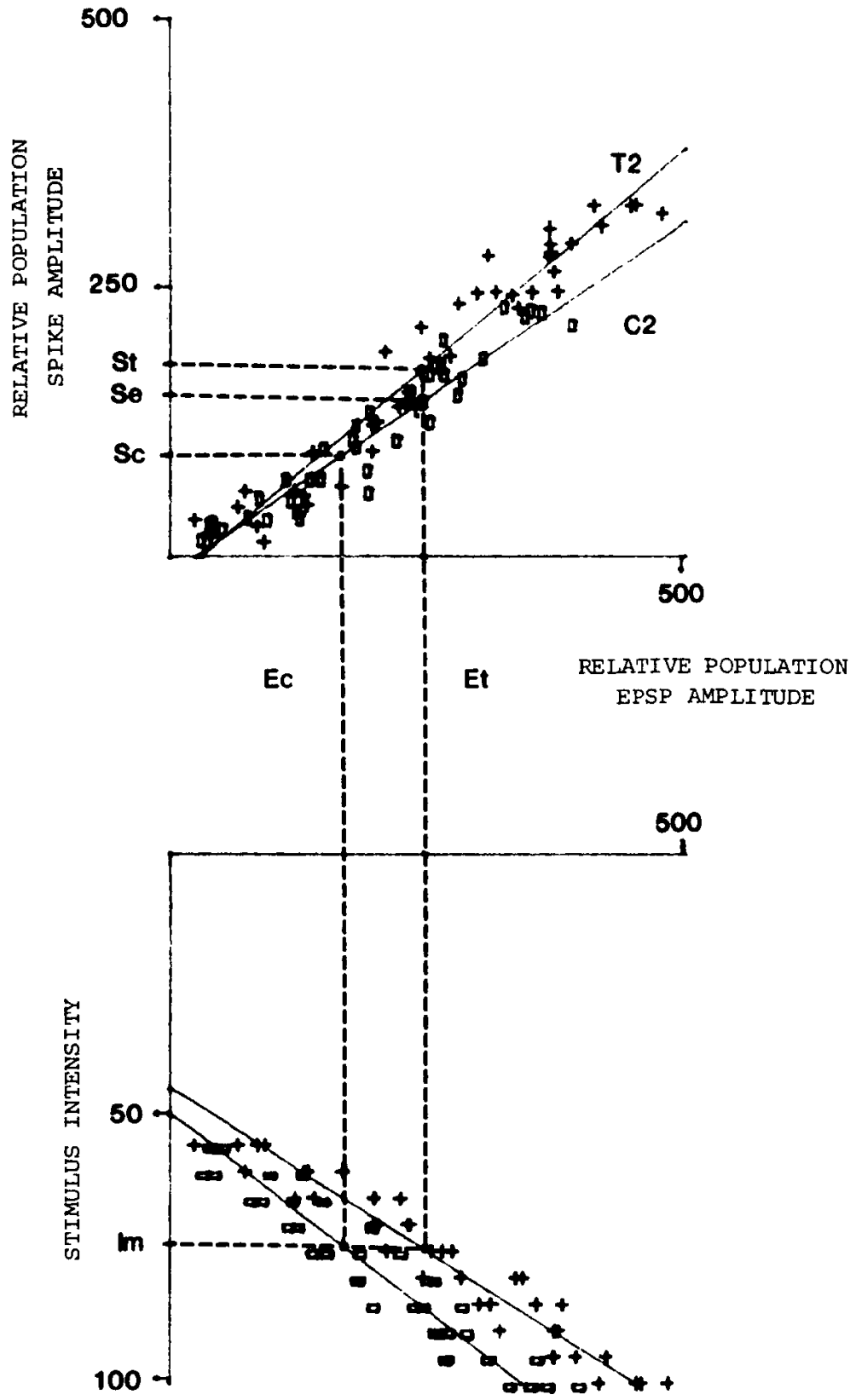

C1

T1

FIG. 4. Determination of percentages of potentiation attributed to synaptic and postsynaptic factors. Population EPSP: 500 relative units, $1.6 \mathrm{mV}$; population spike: 250 relative units, 2.0 $\mathrm{mV}$. See text regarding the calculation of potentiation percentages from slices that exhibit a dissociation of control and test $\mathrm{I} / \mathrm{O}$ functions. 


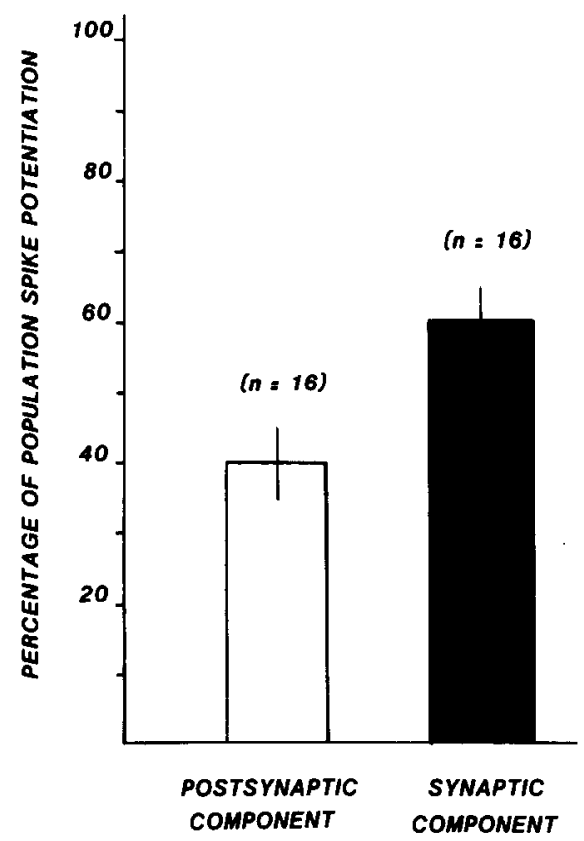

FIG. 5. Percentages of total potentiation attributed to synaptic and postsynaptic factors. Data were derived from slices which exhibited a dissociation of control and test $1 / O$ functions.

alteration in the mechanism of spike initiation (7), by the activation of recurrent excitatory interneurons $(1,8,9)$, or by the presence of dendritic and/ or somatic gap junctions between adjacent pyramidal cells $(2,18,19,21)$. Such gap junctions would effectively depolarize cells that are electrically coupled to discharging neurons and therefore would increase the probability of discharge from the application of the test stimulus.

Another possible postsynaptic mechanism is an alteration in dendritic membrane characteristics that couple synaptic activation and cell discharge. In their study of the potentiation of population responses by opiates, Lynch et al. (16) provided evidence that points to alterations in dendritic membrane properties, which may be the underlying basis of their enhanced neural excitability.

The statistical coincidence for 12 of the 28 slices suggests that for these slices the enhancement of the CAI population spike may be attributed entirely to synaptic facilitation. The absence of an extrasynaptic component of potentiation in these slices may be a result of insufficient numbers of gap junctions in the population encompassed within the transverse slice or insufficient putative feedforward or recurrent excitatory interneurons. A suf- 
ficient number of these interneuronal connections may be needed to allow the detectability of postsynaptic involvement in potentiation.

The potentiation of pyramidal cell responses either by a combination of synaptic and extrasynaptic mechanisms, or by synaptic mechanisms alone, reflects the coactivation of additional neurons within a population. It would be of interest to determine the possible functional significance of such transitory enhancements of activity in neuronal populations as seen, for example, in paired-pulse potentiation or frequency potentiation $(5,20)$. Whereas longterm potentiation of CA1 pyramidal cell responses is thought to be the physiologic substrate of learning processes such as classical conditioning $(3,4)$, it is doubtful that the transitory nature of short-term enhancements would itself be the underlying basis of long lasting changes in behavior. Phenomena such as paired-pulse potentiation, however, do reflect the capacity of a neuronal population to enhance its activity as a result of prior activation. Conditions which lead to the coactivation of a critical mass of neurons may, in turn, produce long-lasting alterations in other regions of brain.

\section{REFERENCES}

1. Andersen, P., G. N. Gross, T. Lomo, and O. Sveen. 1969. Participation of inhibitory and excitatory interncurons in the control of hippocampal output. Pages 415-466 in M. A. BRAZIER, Ed., The Interneuron. Univ. California Press.

2. ANDrew, R. D., C. P. TAYloR, R. W. SNOW, AND F. E. Dudek. 1981. Dye coupling between CA1 pyramidal cells in rat hippocampal slices. Soc. Neurosci. Abstr. 7: 519.

3. BERGER, T. W., B. ALGER, AND R. F. THOMPSON. 1976. Neuronal substrate of classical conditioning in the hippocampus. Science 192: 483-485.

4. BERGER, T. W., AND R. F. THOMPSON. 1978. Identification of pyramidal cells as the critical elements in hippocampal neuronal plasticity during learning. Proc. Natl. Acad. Sci. U.S.A. 75: $1572-1576$.

5. BLISS, T. V. P., AND T. LOMO. 1973. Long-lasting potentiation of synaptic transmission in the dentate area of the anaesthetic rabbit following stimulation of the perforant path. $J$. Physiol. (London) 232: 331-356.

6. BROWNLEE, K. A. 1965. Statistical Theory and Methodology in Science and Engineering, Wiley, New York, pp. 288-298.

7. CALVIN, W. H. 1978. Setting the pace and pattern of discharge: do CNS neurons vary their sensitivity to external input via their repetitive firing process? Fed. Proc. 37: 2165-2170.

8. DiChTER, M., AND W. A. SPENCER. 1969. Penicillin-induced interictal discharges from cat hippocampus. I. Characteristics and topographical features. J. Neurophysiol. 32: 649-662.

9. DiCHTER, M., AND W. A. SPENCER. 1969. Penicillin-induced interictal discharges from the cat hippocampus. II. Mechanisms underlying origin and restriction. J. Neurophysiol. 32: 663-687.

10. Douglas, R. M., AND G. V. GodDard. 1975. Long-term potentiation in the perforant path-granule cell synapse in the rat hippocampus. Brain Res. 86: 205-215.

11. Goddard, G. V., T. V. P. Bliss, H. A. Robertson, and R. S. Sutherland. 1980. Noradrenaline levels affect long term potentiation in the hippocampus. Soc. Neurosci. Abstr. 6: 89. 
12. Lomo, T. 1971. Potentiation of monosynaptic EPSPs in the perforant path-dentate granule cell synapse. Exp. Brain Res. 12: 46-63.

13. LoPeS DA SILVA, F., AND D. E. A. T. ARNOLDS. 1978. Physiology of the hippocampus and related structures. Annu. Rev. Physiol. 40: 185-216.

14. Low, W. C., ANDS. L. BEMENT. 1980. Enhancement of afferent fiber activity in hippocampal slices. Brain Res. 198: 472-477.

15. Low, W. C., S. L. BeMent, AND D. Whitehorn. 1982. Periodic fluctuations in synaptic transmission and enhancement of transmission in hippocampal slices. Brain Res. 231: 438-443.

16. Lynch, G. S., R. A. Gensen, J. L. MCGaugh, K. Davila, and M. W. Oliver. 1981. Effects of enkephalin, morphine, and naloxone on the electrical activity of the in vitro hippocampal slice preparation. Exp. Neurol. 71: 527-540.

17. LYNCH, G., AND P. SCHUBERT. 1980. The use of in vitro brain slices for multidisciplinary studies of synaptic function. Annu. Rev. Neurnsci. 3: 1-22.

18. MACVICAR, B. A., AND F. E. DUDEK. 1981. Electrotonic coupling between pyramidal cells: a direct demonstration in rat hippocampal slices. Science 213: 782-785.

19. SChmalBruch, H., AND JAHNSEN. 1981. Gap junctions on CA3 pyramidal cells of guinea pig hippocampus shown by freeze fracture. Brain Res. 217: 175-178.

20. SCHWARTZKROIN, P. A., AND K. WESTER. 1975. Long-lasting facilitation of a synaptic potential following tetanization in the in vitro hippocampal slice. Brain Res. 89: 107119.

21. TAYlor, C. P., AND F. E. DUdEK. 1981. Physiological evidence for electronic coupling between CA1 pyramidal cells in rat hippocampal slices. Soc. Neurosci. Abstr. 7: 519. 